\title{
AS CONSTANTES BARREIRAS ENFRENTADAS PARA ESCOLHA DO TEMA DE TCC
}

\section{Gabriel Aparecido Zucoloto' Gabriel Amaral Costa ${ }^{2}$ Flávio Pavesi Simão ${ }^{3}$}

Resumo: O presente artigo busca analisar quais são as principais dificuldades encontradas na escolha de um tema para Trabalho de Conclusão de Curso - TCC. Para resolver este problema de pesquisa, foi necessário levantar as principais dificuldades encontradas por alunos na hora de escolher o tema do TCC. Para tanto, foi aplicado um questionário eletrônico, via Google Docs, como método de coleta de dados, cujo resultado fora tabulado e apontado um resultado estatístico para a pesquisa. O público-alvo da pesquisa foram 130 alunos do curso superior de análise de sistema de uma instituição de ensino público. Com o resultado encontrado a partir dos questionários, nota-se dificuldades como o a inexperiência das normas a serem seguidas para formatação de projetos, além do pouco conhecimento sobre o tema que gostariam de abordar, pode-se apurar que a escolha para um tema pode ser muito difícil levando-se em consideração fatores como conhecimento adquirido durante o curso e tempo para se dedicar ao trabalho.

Palavras-chave: Pesquisa; Barreiras; TCC; Tema; Fatores.

\footnotetext{
${ }^{1}$ Tecnologia em Análise e Desenvolvimento de Sistemas/ Instituto Federal do Espírito Santo - Campus de Alegre, Brasil. E-mail: bielaparecidozucoloto@gmail.com.

${ }^{2}$ Tecnologia em Análise e Desenvolvimento de Sistemas / Instituto Federal do Espírito Santo - Campus de Alegre, Brasil. E-mail: gabriel_costa_19@hotmail.com.

${ }^{3}$ Tecnologia em Análise e Desenvolvimento de Sistemas / Instituto Federal do Espírito Santo - Campus de Alegre, Brasil. E-mail: fpavesi.simao@gmail.com.
} 